\title{
ANALISIS PENGARUH MADDEN JULIAN OSCILLATION (MJO) TERHADAP ANOMALI CURAH HUJAN DI WILAYAH NGURAH RAI
}

\author{
Wendel Jan Pattipeilohy ${ }^{1}$, Femmy Marsitha $B^{2}$, Devina Putri Asri ${ }^{3}$ \\ ${ }^{1}$ Stasiun Klimatologi Manokwari Selatan, Papua Barat \\ ${ }^{2}$ Subbidang Analisis Proyeksi Iklim BMKG, Jakarta \\ ${ }^{3}$ Sekolah Tinggi Meteorologi Klimatologi dan Geofisika, Jakarta \\ Email:wendeljan89@gmail.com
}

\begin{abstract}
ABSTRAK
Madden Julian Oscillation (MJO) merupakan suatu gelombang atau osilasi non seasonal yang terjadi di lapisan troposfer yang bergerak dari barat ke timur dengan periode osilasi kurang lebih 30-60 hari. Fenomena ini sangat berdampak terhadap kondisi anomali curah hujan pada suatu wilayah yang dilaluinya. Dalam penelitian ini delapan fase MJO dikelompokan menjadi 4 bagian sesuai dengan pergerakannya yaitu fase 1 dan 8 (Western and Africa), fase 2 dan 3 (Indian Ocean), fase 4 dan 5 (Maritime Continent), fase 6 dan 7 (Western Pacific). Data yang digunakan dalam penelitian ini yaitu data curah hujan periode 19962015 dan data MJO periode yang sama. Lokasi penelitian yaitu wilayah Ngurah Rai. Data curah hujan dihitung anomalinya lalu dipisahkan antara anomali positif dan negatif lalu disandingkan dengan fase MJO aktif. Penelitian ini bertujuan untuk menganalisis porsentase kelompok fase MJO mana yang mendominasi anomali curah hujan pada saat anomali positif maupun negatif. Hasil kajian menunjukan persentase kejadian anomali curah hujan positif dominan terjadi saat fase MJO berada di Maritime Continent sebesar $36 \%$. Kemudian persentase kejadian anomali curah hujan negatif dominan terjadi saat MJO berada pada fase Indian Ocean dengan porsentasi sebesar $33 \%$.
\end{abstract}

Kata kunci: MJO, anomali, persentase, benua maritim

\begin{abstract}
Madden Julian Oscillation (MJO) is a non-seasonal wave or oscillation in the troposphere which moves from west to east with an oscillation period of approximately 30-60 days. This phenomenon influences the condition of rainfall anomaly in the region passed. This research has 8 phases of MJO which are categorized into 4 sections according to their movements namely phases 1 and 8 (Western and Africa), phases 2 and 3 (Indian Ocean), phases 4 and 5 (Maritime Continent), phases 6 and 7 (Western Pacific). The data used in this study are rainfall data in 1996-2015 and MJO data for the same period. This research is located in Ngurah Rai. The anomaly of the rainfall is defined into positive and negative anomaly, then they are accumulated with the active MJO phases. This study aims to analyze the percentage of MJO phase groups which dominates rainfall in positive or negative anomaly. The result shows that the percentage of positive anomaly rainfall happens most in MJO phase, Maritime Continent, that is 36\%. While the percentage of negative anomaly rainfall dominates at the time MJO is in the phase of Indian Ocean,33\%.
\end{abstract}

Keywords: MJO, anomaly, percentage, maritime continent 


\section{PENDAhULUAN}

Kawasan Indonesia merupakan salah satu kawasan yang berperan penting dalam pembentukan cuaca dan iklim global. Hal itu disebabkan karena kondisi Indonesia sebagai wilayah maritim yang memiliki kawasan lautan lebih luas dari daratan.. Kawasan ini diduga sebagai tempat penyimpanan bahang (panas) baik yang berupa sensible heat maupun latent heat bagi pembentukan awan-awan hujan seperti cumulonimbus. (Hermawan, 2002).

Hujan menjadi salah satu unsur iklim yang paling sering dikaji di Indonesia karena memiliki tingkat keragaman sangat tinggi baik secara waktu maupun secara tempat. Curah hujan di Indonesia umumnya dipengaruhi oleh fenomena sirkulasi atmosfer baik skala global, regional, maupun lokal. Salah satu fenomena global yang mempengaruhi cuaca dan iklim Indonesia adalah Madden Julian Oscillation (MJO) . MJO sebagian besar berpengaruh terhadap pola curah hujan di Indonesia dan daerah sekitarnya yang dilintasi oleh garis khatulistiwa.(Geerts dan Wheeler, 1998). Peristiwa MJO pertama kali terdeteksi oleh Madden dan Julian menggunakan data rawinsodne dengan periode harian di Pulau Kanton, Republik Kiribati (3S, 172W) dan Singapura (1.3N, 103.8E) selama 10 tahun.( Madden dan Jullian , 1971).MJO atau disebut juga osilasi intraseasonal MJO, adalah elemen terbesar dari variabilitas intraseasonal dengan periode 30-90 hari di atmosfer wilayah tropis,dengan karakteristik utama yakni adanya wilayah peningkatan dan penurunan curah hujan yang bergerak berpasangan mengelilingi bumi dari barat ke timur, dan umumnya terjadi di sepanjang Samudera Hindia hingga Samudera Pasifik. ( Madden dan Jullian , 1994) Karakteristik MJO dikaji lebih dalam dengan menggunakan struktur 3 dimensi yaitu ketika suppressed convective kuat dari lautan Hindia hingga lautan Pasifik Tengah, anomali siklonik pada level $200 \mathrm{mb}$ bergerak mengikuti daerah dari suppressed convective.(Rui dan Wang, 1990).

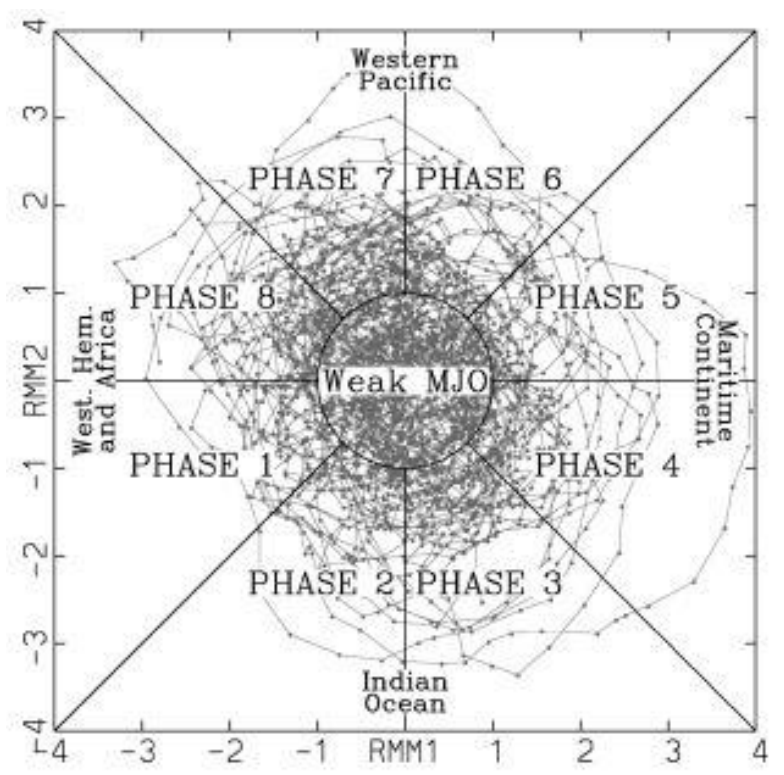

Gambar 1. Ttitik Ruang Fase untuk Semua Hari yang Tersedia di Musim DJF dari Tahun 1974 hingga 2003.

Sumber: Wheeler dan Hendon (2004)

Berdasarkan perilaku lead-lag indeks RMM, mendiagnosis keadaan MJO sebagai titik ruang fase dua dimensi yang didefinisikan oleh RMM1 dan RMM2 akan lebih mudah. Gambaran ini ditunjukkan pada semua hari di bulan Desember-Januari-Februari (DJF) pada Gambar 1.1. Nilai yang mewakili hari berurutan digabungkan dengan garis. Banyak dari hari-hari berurutan membentuk lingkaran berlawanan arah jarum jam di sekitar titik asal, yang secara signifikan menunjukkan propagasi MJO ke arah timur. Lingkaran amplitudo besar menandakan siklus kuat MJO, sementara aktivitas MJO yang lemah muncul sebagai gerakan yang agak acak di dekat titik asal. Untuk penguraian unsur dan aplikasi lain, fase bernomor didefinisikan pada gambar 1.1, bersama dengan indikasi lokasi peningkatan konveksi MJO untuk setiap kuadran diagram. 4 kelompok fase sesuai dengan pewilayahan diagram fase MJO pada Gambar 1.1 , yaitu fase $8 \& 1$ di Western Hemisphere and Africa, fase $2 \& 3$ di Indian Ocean, fase $4 \& 5$ di Maritime Continent, fase $6 \& 7 \mathrm{di}$ Western Pacific. (Wheeler dan harry, 2004) 
Ngurah Rai merupakan wilayah yang berada di Pulau Bali. Letak geografis yang berada di tengah benua maritim Indonesia ini menjadikan Ngurah Rai sebagai kawasan yang menarik untuk ditelaah karakteristik meteorologinya. Curah hujan di pulau Bali secara umum termasuk ke dalam pola curah hujan monsunal - Pola curah hujan ini ditandai dengan satu puncak musim hujan ( unimodial) yaitu antara bulan Desember, Januari dan Februari, serta mempunyai perbedaan yang jelas antara musim hujan dan musim kemarau. (Bayong, 1999)

Di Indonesia beberapa penelitian mengenai MJO sudah mulai berkembang. Talama dkk melakukan penelitian di Makassar bahwa MJO berpengaruh kecil terhadap peningkatan dan penurunan curah hujan di Kota Makassar. (Tallama dkk., 2016). Ardianto melakukan analisis fase MJO terhadap anomali curah hujan dasarian di Pontianak bahwa MJO dominan pada fase 1-4 menyebabkan anomali curah hujan positif yang menandakan curah hujan meningkat, sedangkan MJO dominan pada fase 5-8 menyebabkan anomali negatif yang menandakan curah hujan menurun. (Ardianto dan Randy, 2009). Seto menemukan bahwa fase aktif MJO memiliki korelasi terjadinya intensitas curah hujan yang tinggi tehadap wilayah yang dilaluinya. (Seto, 2004). Prianti melakukakan penelitian bahwa MJO berpengaruh lemah terhadap curah hujan yang terjadi di Ngurah Rai bali. (Prianti dan Ni Putu, 2014). Berdasarkan penelitian-penelitian tersebut, penulis mengambil wilayah Ngurah Rai untuk melihat seberapa besar pengaruh MJO terhadap anomali curah hujan dasariannya selama periode 1996-2015.

\section{METODE}

Data yang digunakan dalam penelitian ini yaitu data curah hujan harian periode 1996-2015 yang dikonversi menjadi curah hujan dasarian (10 harian) wilayah Ngurah Rai dan data MJO yang terdiri dari fase MJO dan amplitude dengan periode 1996-2015 yang diunduh melalui website Bureon of Meteorology (BoM) Australia pada link : http://www.bom.gov.au/climate/mjo/. (MJO, 1996-2016)
Kemudian fase MJO yang terdiri dari 8 fase dibagi menjadi 4 wilayah kelompok sesuai dengan pergerakan MJO yang terdapat pada Diagram Wheeler and Hendon (Wheeler dkk., 2004) yaitu West.Hem and Africa (fase 8 \& 1), Indian Ocean (fase $2 \&$ 3), Maritime Continent (fase $4 \& 5$ ) dan Western Pacific (fase $7 \& 8$ ).

Metode yang digunakan terdiri dari 4 langkah, yang pertama yaitu mengkonversi jumlah curah hujan harian menjadi dasarian seperti pada persamaan (1), yaitu:

$$
\text { CH Dasarian }=X_{1}+X_{2}+X_{3}+\cdots+X_{10}
$$

Keterangan:

$\mathrm{X}=$ curah hujan harian (mm).

Langkah kedua yaitu menghitung rata-rata curah hujan setiap dasarian pada persamaan (2), yaitu:

$$
\bar{X}=\frac{\sum_{i=1}^{n} x_{i}}{n}
$$

Keterangan:

$\overline{\mathrm{X}}=$ Rata-rata curah hujan dasarian,

$\mathrm{x}_{\mathrm{i}}=$ Curah hujan dasarian

$\mathrm{n}=$ Jumlah tahun.

Langkah yang ketiga yaitu menghitung anomali curah hujan perdasarian dengan persamaan (3), yaitu:

$$
\text { Anomali } C H=X-\bar{X}
$$

Keterangan:

$\mathrm{X}=$ Curah hujan dasarian

$\overline{\mathrm{X}} \quad=$ Rata-rata curah hujan dasarian.

Langkah keempat yaitu metode filtrasi yaitu memisahkan suatu komponen induk menjadi beberapa bagian komponen sesuai dengan kriteria atau parameter yang terlah ditentukan. (Santoso, 2006) Dalam penelitian ini filtrasi yang dilakukan bagi kedalam dua kategori antara anomali positif dan anomali negatif untuk melihat pengaruh MJO terhadap anomali 
curah hujan pada masing-masing kelompok fase yang telah ditentukan.

Langkah kelima yaitu metode korelasi Pearson seperti pada persamaan (4) dengan adanya variabel bebas dan variable terikat seperti berikut.

$$
\mathrm{r}=\frac{\sum x y-\frac{1}{n} \sum x \sum y}{\left[\sum x^{2}-\frac{1}{n}\left(\sum x\right)^{2}\right]^{\frac{1}{2}}\left[\sum y^{2}-\frac{1}{n}\left(\sum y\right)^{2}\right]^{\frac{1}{2}}}
$$

Keterangan:

$\mathrm{x} \quad=$ Anomali curah hujan

$\mathrm{y} \quad=$ Amplitudo MJO.

$\mathrm{r} \quad$ =harga koefisien korelasi

Nilai $r$ tidak lebih dari harga $(-1 \leq r \leq 1)$. Apabila $r=-1$ menandakan bahwa korelasi negatif sempurna (berbanding terbalik anatara dua variabel tersebut), $r=0$ menandakan tidak ada korelasi dan $r=1$ menandakan korelasi sempurna positif sangat kuat (berbanding lurus antara dua variabel tersebut). (Benedict dan Randall, 2007)

Pada gambar 2 merupakan kerangka berpikir untuk menjelaskan uraian dari proses yang akan diidentifikasi dalam penelitian yaitu

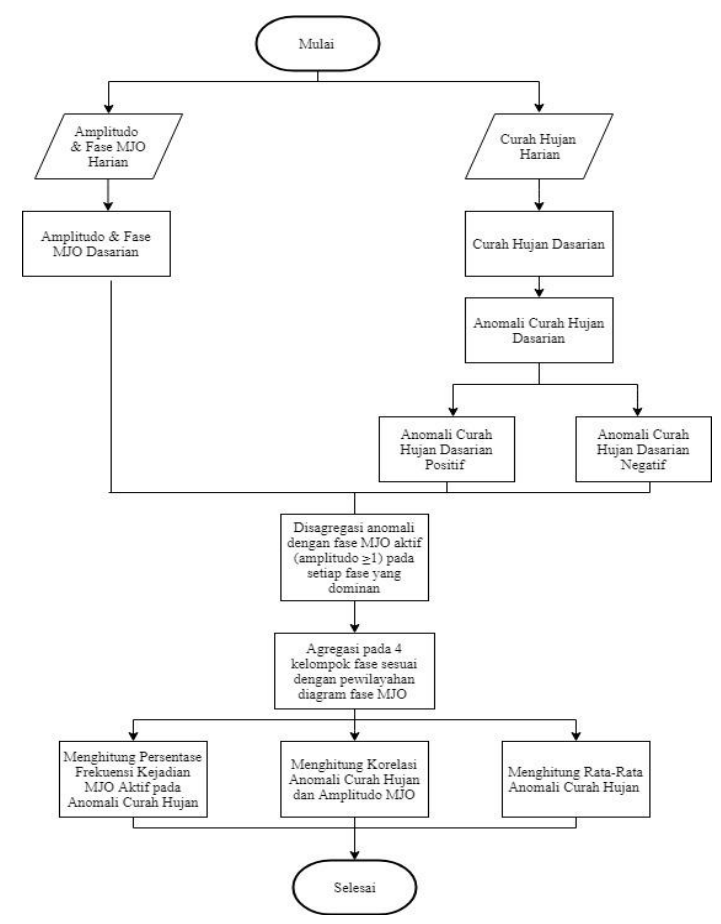

sebagai berikut:

Gambar 2. Diagram alir pengelolahan data

\section{HASIL DAN PEMBAHASAN}

Karakteristik curah hujan di wilayah Ngurah Rai sesuai dengan Gambar 3 menunjukan pola hujan monsunal yang artinya wilayah Ngurah Rai dipengaruhi oleh angin monsun sehingga terdapat satu puncak musim hujan dan satu puncak musim kemarau. Berdasarkan data curah hujan periode 1996-2015, secara umum curah hujan tertinggi terjadi di bulan Januari dasarian III sebesar $144.8 \mathrm{~mm}$ dan terendah terjadi di bulan Agustus dasarian II sebesar 3 $\mathrm{mm}$.

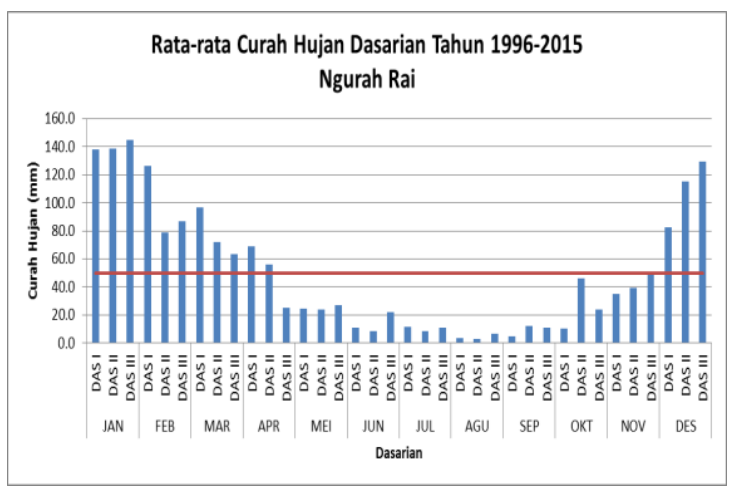

Gambar 3. Grafik rata-rata curah hujan dasarian tahun 1996-2015 di wilayah Ngurah Rai

Hasil filtrasi fase MJO dominan yang terjadi pada setiap dasarian di 4 kelompok fase selama periode 1996-2015 menunjukkan umumnya saat MJO aktif, curah hujan di Ngurah Rai mengalami pengurangan terhadap rata-ratanya (anomali negatif) dengan total frekuensi kejadian sebanyak 207 kejadian sedangkan untuk penambahan curah hujan terhadap rataratanya (anomali positif) terjadi sebanyak 172 kali. Frekuensi kejadian anomali curah hujan positif maupun negatif pada 4 kelompok fase MJO aktif yang dinyatakan dalam persen dapat dilihat pada Gambar 4 dan 5. 
Porsentase Kejadian MJ0 Aktif pada Anomali Curah Hujan Positif Tahun 1996-2015

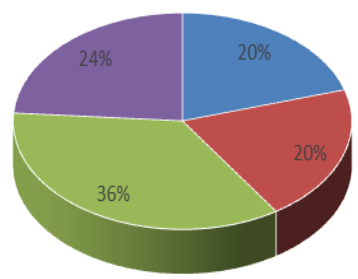

- FASE 8 \& 1 (WEST.HEM \& AFRICA) - FASE 2 \& 3 (INDIAN OCEAN)

- FASE 4 \& 5 (MART IME CONTINENT) - FASE 6 \& 7 (WESTREN PASIFIC)

Gambar 4. Persentase kejadian MJO aktif pada anomali hujan positif1996-2015 di Ngurah Rai

Porsentase Kejadian MJ0 Aktif pada Anomali Curah Hujan Negatif Tahun 1996-2015

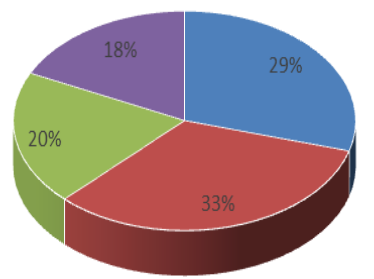

- FASE 8 \& 1 (WEST. HEM \& AFRICA) - FASE 2 \& 3 (INDIAN OCEAN)

• FASE 4 \& 5 (MART IME CONTINENT) • FASE 6 \& 7 (WESTREN PASIFIC)

Gambar 5. Persentase kejadian MJO aktif pada anomali hujan negatif tahun 1996-2015 di Ngurah Rai

Pada gambar 4 saat MJO aktif pada empat kelompok fase, yang dominan menambah curah hujan terhadap rata-ratanya di wilayah Ngurah Rai adalah fase Maritime Continent (Fase 4 \& 5) sebesar 36\% saat enhanced convective. Sedangkan pada saat MJO aktif di fase $2 \& 3$ (Samudra Hindia) dan fase $8 \& 1$ yaitu dibelahan bumi barat dan Africa masingmasing sebesar $20 \%$ dan untuk fase $6 \& 7$ (Pasifik bagian Barat) sebesar 24\% menambah curah hujan ketika MJO aktif.

Pada gambar 5 menunjukkan untuk anomali curah hujan negatif ketika MJO aktif pada masing-masing kelompok fase, MJO dominan mengurangi curah hujan terhadap rata-ratanya saat aktif di fase $2 \& 3$ (Samudra Hindia) sebesar 33\%. Saat MJO aktif di Fase $8 \& 1$ dapat mengurangi curah hujan sebesar $29 \%$. Sedangkan untuk wilayah Mariime Continent dan Pasifik bagian Barat pengurangan curah hujan terhadap rata-ratanya hanya sebesar $20 \%$ dan $18 \%$ selama 15 tahun. Hal ini sejalan dengan penelitian sebelumnya yang menyebutkan bahwa mekanisme penjalaran MJO yang dianalisis berdasarkan pergerakkannya maka akan terjadi konveksi yang kuat (deep convection) sehingga terjadi pertumbuhan awan konvektif dan presipitasi maksimum pada fase 3 (Indian Ocean) sedangkan pada fase selanjutnya terjadi disipasi konvektif yang disebut fase suppressed sehingga menyebabkan wilayah tersebut (Maritime Continent) kering atau dapat dikatakan anomali curah hujan dominan negatif. (Santoso, 2006)

Secara umum besarnya persentase anomali hujan positif dan negatif tidak jauh berbeda dan dibawah 50\%. Dengan melihat grafik frekuensi kejadian anomali curah hujan dasarian pada gambar 6 dapat dikatakan bahwa kejadian MJO aktif di semua kelompok terdistribusi menyebabkan anomali $0-100 \mathrm{~mm} /$ dasarian saat anomali positif dominan terjadi pada fase $4 \&$ 5 dengan total 46 frekuensi kejadian dan saat anomali negatif dominan terjadi pada fase $2 \&$ 3 dengan total 68 kejadian secara berturutturut. 


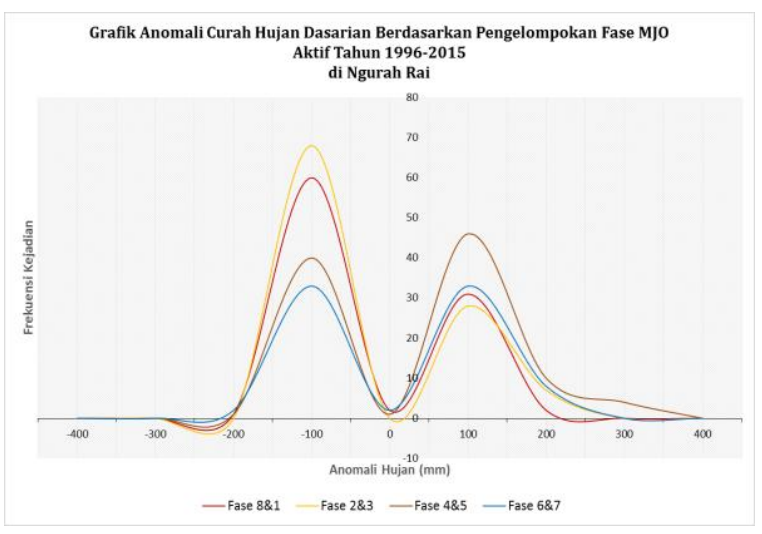

Gambar 6. Grafik anomali curah hujan dasarian setiap kelompok fase MJO aktif tahun 1996-2015 di

Ngurah Rai

Berdasarkan tabel 1 dapat dilihat bahwa dari segi jumlahnya umumnya pada semua fase dominan menyebabkan penambahan curah hujan selama periode 15 tahun di Ngurah Rai. Pada saat MJO aktif dominan di fase $4 \& 5$ rata-rata penambahan sebesar 60.7 $\mathrm{mm}$ /dasarian dan penambahan rata-rata curah hujan terendah terjadi saat fase $8 \& 1$ sebesar $41.2 \mathrm{~mm} /$ dasarian. Kemudian untuk anomali negatif rata-rata terbesar terjadi saat fase $\mathrm{MJO}$ aktif di fase $6 \& 7$ sebesar $-31.8 \mathrm{~mm} /$ dasarian dan yang terkecil terjadi saat fase $8 \& 1$ dengan rata-rata sebesar $-20.8 \mathrm{~mm} /$ dasarian.

Tabel 1. Rata-rata penambahan dan pengurangan curah hujan di Maros pada setiap kelompok fase MJO aktif

\begin{tabular}{lll}
\hline Fase & \multicolumn{2}{l}{ Rata-rata $(\mathbf{m m} /$ dasarian$)$} \\
& Penambahan & Pengurangan \\
\hline $8 \& 1$ & 41.2 & -20.8 \\
$2 \& 3$ & 57.2 & -24.0 \\
$4 \& 5$ & 60.7 & -21.1 \\
$6 \& 7$ & 50.0 & -31.8 \\
\hline
\end{tabular}

Pada tabel 2, nilai korelasi terbesar terjadi di bulan September dan November dasarian II sebesar 0.5 dan 0.52 atau sekitar $23 \%$ pengaruh mjo terhadap penambahan dan pengurangan curah hujan di Ngurah Rai. Sedangkan pada waktu waktu lainnya pengaruh MJO tidak terlihat. Namun, jika ditinjau dari segi kelompok fase mana yang paling berpengaruh pada tabel 3 menunjukkan nilai yang sangat kecil atau pengaruh MJO tidak signifikan pada semua kelompok fase, yaitu dibawah 0.5. Hal ini selaras dengan besaran frekuensi anomali curah hujan yang hampir seragam pada setiap kelompok fase dominan.

Tabel 2. Nilai korelasi indeks RMM (amplitudo) MJO aktif dengan anomali curah hujan di Ngurah Rai periode 1996-2015

\begin{tabular}{lccc}
\hline \multicolumn{1}{c}{ Bulanan } & \multicolumn{3}{c}{ Dasarian } \\
& I & II & III \\
\hline Januari & -0.27 & 0.01 & 0.36 \\
Februari & -0.27 & -0.01 & 0.01 \\
Maret & -0.21 & -0.20 & -0.14 \\
April & 0.04 & -0.13 & -0.34 \\
Mei & -0.31 & -0.18 & -0.27 \\
Juni & -0.16 & -0.42 & 0.21 \\
Juli & -0.10 & -0.17 & 0.31 \\
Agustus & 0.47 & -0.38 & -0.22 \\
September & 0.01 & -0.50 & -0.11 \\
Oktober & 0.02 & -0.38 & -0.46 \\
November & 0.33 & 0.52 & 0.36 \\
Desember & 0.13 & 0.21 & -0.36 \\
\hline
\end{tabular}

Tabel 3. Nilai korelasi indeks RMM (amplitudo) MJO aktif dengan anomali curah hujan di Ngurah Rai pada setiap kelompok fase

\begin{tabular}{ccc}
\hline \multirow{2}{*}{ Fase } & \multicolumn{2}{c}{ Nilai korelasi } \\
& Penambahan & Pengurangan \\
\hline $8 \& 1$ & 0.20 & -0.27 \\
$2 \& 3$ & -0.16 & -0.01 \\
$4 \& 5$ & -0.15 & -0.17 \\
$6 \& 7$ & -0.07 & -0.34 \\
\hline
\end{tabular}




\section{KESIMPULAN}

Berdasarkan hasil dan pembahasan, dapat disimpulkan bahwa selama MJO aktif pada fase Maritime Continent periode 1996-2015 diwilayah Ngurah Rai, banyak menyebabkan terjadinya anomali curah hujan positif dengan persentase sebesar $36 \%$. Sedangkan saat MJO aktif di fase Indian Ocean banyak menyebabkan anomali curah hujan negatif dengan persentase sebesar $33 \%$. Sementara dari segi jumlah curah hujan, rata-rata penambahan anomali curah hujan terbesar terjadi saat MJO dominan aktif di fase 4 dan 5 (Maritime Continent) yaitu $60.7 \mathrm{~mm} /$ dasarian dan rata-rata pengurangan anomali curah hujan negatif terbesar terjadi saat MJO dominan aktif di fase 6 dan 7 (Western Pasific) yaitu -31.8 $\mathrm{mm}$ /dasarian. Kemudian, untuk keeratan hubungan setiap dasarian, sebesar hampir 23\% MJO mempengaruhi anomali curah hujan pada bulan September dan November dasarian II dengan korelasi 0.52. Namun semua kelompok fase secara umum tidak terlalu signifikan pengaruhnya terhadap anomali curah hujan di Ngurah Rai.

\section{UCAPAN TERIMA KASIH}

Penulis menyampaikan terimakasih yang sebesar-besarnya kepada Stasiun Klimatologi Jembrana Bali atas sumbangsih data curah hujan harian periode 1996-2015 di Wilayah Ngurah Rai Bali.

\section{DAFTAR PUSTAKA}

Hermawan, E. 2002. Perbandingan Antara Radar Atmosfer Khatulistiwa dengan Middle and Upper Atmosphere Radar dalam Pemantauan Angin Zonal dan Angin Meridional. Warta LAPAN. 4 (1) : 8-16.

Geerts B. dan M. Wheeler, 1998: The Madden Julian Oscillation [online], http://www.das.uwyo.edu/ geerts/cw x/notes/chap12/mjo.html, diakses tanggal 12 Februari 2019

Madden R.A., Julian P.R., 1971. Description of 40-50 Day Oscillation in the Zonal Wind in the Tropical Pacific. Journal of Atmospheric Science, 28: 702-708

Madden, R.A., Jullian, P.R. 1994.. Observations of the 40-50-Day Tropical Oscillation - A Review. Monthly Weather Review, 122(5), 814-837. doi: 10.1175/15200493(1994)1222.0.CO;2

Rui, H. \& B. Wang.1990.Development characteristics and dynamic structure of tropical intraseasonal convection anomalies. J Atmos Sci, 47, 357-379.

Wheeler, Matthew C., and Harry H. Hendon.2004. An all-season real-time multivariate MJO index: Development of an index for monitoring and prediction. Monthly Weather Review 132.8: 1917-1932.

Bayong Tjasyono, H.K. 1999. Klimatologi Umum. Penerbit ITB. Bandung.

Tallama, dkk. 2016. Analisis Pengaruh Madden Julian Oscillation terhadap Curah Hujan di Kota Makassar. Makassar.

Ardianto, Randy. 2009. Analisa Dampak Madden Julian Oscillation terhadap Curah Hujan di Pontianak. Jakarta

Seto T . H.2004. Pengaruh Osilasi MaddenJulian Terhadap Variabilitas Curah Hujan Tropis. Jurnal Sains \& $T$ eknologi Modifikasi Cuaca I(V), 5558.

Prianti, Ni Putu Nonik. 2014.Analisa Madden Julian Oscillation terhadap Karakteristik Curah Hujan di Ngurah Rai Bali. Buletin Meteo Ngurah Rai. Bali.

Data MJO periode 1996-2016. http://www.bom.gov.au/climate/mjo/, diakses tanggal 11 Januari 2019

Wheeler, Matthew C., and Harry H. Hendon.2004. An all-season real-time multivariate MJO index: Development of an index for monitoring and prediction. Monthly Weather Review 132.8: 1917-1932 
Santoso, S.2006. Menguasai Statistik Di Era Informasi Dengan SPSS 14. Jakarta: PT. Elex Media Komputindo Kelompok Gramedia.

Benedict, J. dan D.A.Randall, 2007 : Observed characteristics of the $M J O$ relative to maximum rainfall. J Atmos. Sci., 64,23322354 